7. Навчальні програми для загальноосвітніх навчальних закладів із навчанням українською мовою. 1-4 класи. - Київ : Видавничий дім «Освіта», 2012. - С. 10-70. 8. Передрій Г. Р. Змішаний розбір як прийом повторення вивченого в 4 класі / Г. Р. Передрій // Українська мова і література в школі. - 1980. - № 3. - С. 12-16. 9. Розвиток життєвих компетентностей на уроках української мови / упоряд. Л. В. Бутрин. - Тернопіль-Харків : Ранок, 2011. - 144 с. 10. Чабайовська М. І. Мовний розбір у вищій та початковій школі: [навч.-мет. посіб.] / М. І. Чабайовська - Тернопіль : Мальва-ОСО, 2008. - 124 с.

УДК 37.013 .42

Валентина Костина

\title{
ФОРМИРОВАНИЕ ОБРАЗОВАТЕЛЬНОГО ПРОСТРАНСТВА ПРОФЕССИОНАЛЬНОЙ ПОДГОТОВКИ БУДУЩИХ СОЦИАЛЬНЫХ ПЕДАГОГОВ К РАБОТЕ С ДЕЗАДАПТИРОВАННЫМИ ДЕТЬМИ И МОЛОДЕЖЬЮ
}

Костіна В. В. Фурмування освітнього простору професійної підготовки майбутніх соціальних педагогів до роботи з дезадаптованими дітьми та молоддю.

У статті висвітлено зміст підготовки майбутніх соціальних педагогів до роботи 3 дезадаптованими дітьми та молоддю в умовах професійно спрямованого освітнього простору; окреслено особливості підготовки майбутніх соціальних педагогів в умовах організації роботи студентського наукового товариства; наведено результати експериментальних досліджень рівня професійної підготовки майбутніх соціальних педагогів до роботи з дезадаптованими дітьми та молоддю.

Ключові слова: соціальний педагог, дезадаптовані діти й молодь, освітній простір, професійна підготовка майбутніх соціальних педагогів.

Костина В. В. Формирование образовательного пространства профессиональной подготовки будущих социальных педагогов к работе с дезадаптированными детьми и молодежью. В статье раскрыто содержание подготовки будущих социальных педагогов к работе с дезадаптированными детьми и молодежью в условиях профессионально направленного образовательного пространства; определены особенности подготовки будущих социальных педагогов в условиях организации работы студенческого научного общества; приведены результаты экспериментальных исследований уровня профессиональной подготовки будущих социальных педагогов к работе с дезадаптированными детьми и молодежью.

Ключевые слова: социальный педагог, дезадаптированные дети и молодежь, образовательное пространство, профессиональная подготовка будущих социальных педагогов.

Kostina V. V. Formation of educational environment of future social teachers professional training to work with maladjusted children and youth.

In this article the training content of future social teachers to work with maladjusted children and youth in the conditions of professionally directed educational environmen has been dicussed; the features of future social teachers training under the organization of work of student's scientific society have been defined; the results of experimental research of the professional training level of future social teachers to work with maladjusted children and youth have been shown.

Key words: social teacher, maladjusted children and youth, educational environment, 
professional training of future social teachers.

В условиях новых социальных изменений, которые затрагивают все стороны жизни современного общества, повышается роль и значение подготовки профессионалов, способных не только воспроизводить накопленные в процессе обучения знания и умения, но и самостоятельно их пополнять, стремиться к их творческой интерпретации. Количество социальных проблем постоянно возрастает и затрагивает все более молодую аудиторию, что обусловливает необходимость повышения эффективности профессиональной подготовки будущих социальных педагогов, способных путем создания воспитывающей среды усилить социализирующее влияние факторов образовательного пространства учебно-воспитательных учреждений и других социальных институтов.

Анализ научных исследований по проблеме подготовки будущих социальных педагогов к работе с дезадаптированными детьми и молодежью показал, что исследованы такие ее аспекты: организация воспитывающей среды для детей и молодежи (Н. Новикова, И. Подласый, В. Ромайкин, Н. Селиванова); характеристики воспитывающей среды и воспитательного пространства (Е. Бондаревская, А. Лукина, Н. Щуркова); создание социокультурной воспитывающей среды общеобразовательного учреждения (В. Веснин, Л. Клепачевская, И. Левицкая); создание воспитывающей среды для дезадаптированных детей (В. Григорова, Р. Овчарова, А. Петрынин); подготовка будущих педагогов к работе с дезадаптированными детьми (С. Беличева, Т. Молодцова, А. Ящук); теоретикометодологические основы профессиональной подготовки будущих социальных педагогов (А. Беспалько, И. Зверева, А. Капская, Г. Лактионова, Л. Мищик, В. Полищук, С. Харченко и др); отдельные аспекты профессиональной подготовки будущих социальных педагогов (А. Гуренко, А. Денисюк, И. Доброскок, Т. Лесина, А. Лисовец, А. Луганцева, Н. Максимовская, А. Михайленко, А. Остапчук, Г. Першко, Л. Пундик, Е. Седова, Л. Ткаченко, З. Фалинськая, И. Фирсова, Т. Шанскова, А. Яворская); вопросы профессиональной подготовки будущих социальных педагогов к работе с детьми и молодежью с девиантным поведением (Р. Новгородский, А. Тютюнник, А. Чусова). Несмотря на весомые научные наработки ученых по проблеме, вышеперечисленные аспекты только частично раскрывают особенности формирования готовности будущих социальных педагогов к профессиональной деятельности с дезадаптированными детьми и молодежью.

Анализ практической социально-педагогической деятельности по проблеме работы с дезадаптированными детьми и молодежью показал, что социальные педагоги должны осуществлять комплексную профилактическую деятельность, направленную на своевременное выявление и нейтрализацию действия виктимогенных факторов в среде, в которой осуществляется их социализация, а также коррекционную деятельность с учащимися «группы социального риска», имеющими виктимные личностные черты и характеристики с целью предупреждения появления состояния их дезориентации, которое может обусловить возникновение девиаций. Тогда основной задачей специалистов в сфере социального воспитания является создание воспитывающей среды, которая усилит социализирующее влияние на дезадаптированных детей и молодежь и способствует развитию их социальности.

Цель статьи: определить сущность и особенности подготовки будущих социальных педагогов к работе с дезадаптированными детьми и молодежью в условиях профессионально ориентированного образовательного пространства организации научной деятельности студентов. 
Как показывает анализ научной и методической литературы, общераспространенным является термин «социальная среда», но единого мнения относительно определения его сущности нет. Так, в словаре терминов по общей и социальной педагогике (А. Воронин) [2] «среда социальная»определяется как конкретное проявление общественных отношений, в которых развиваются конкретное лицо, социальная общность; социальные условия их развития. Автор предлагает такую классификацию проявлений социальной среды: 1) по виду общности (общественная формация, класс, группа); 2) по виду группы (семейная, учебная, общественная, трудовая, спортивная, военная и т. д.); 3) по формирующим действиям (та, что детерминирует, тренирует, дает упражнения, поучительная, воспитывающая, перевоспитывающая); 4) по способу воздействия на форму сознания (правовая, нравственная, эстетическая, научная); 5) по возрасту (сверстники, старшие, младшие, смешанная); 6) по отношению к среде (положительная, вызывающая желание подражать; безразличная; отрицательная, вызывающая протест); 7) по социальной направленности (социализирующая, асоциальная); 8) по степени контактов (непосредственная, опосредованная).

В большом словаре по социологии термин «социальная среда» рассматривают в двух значениях [1]: 1) совокупность материальных, экономических, социальных, политических и духовных условий существования, формирования и деятельности индивидов и социальных групп, где различают макросреду (социально-экономическая система в целом) и микросреду (непосредственное социальное окружение); 2) часть окружающей среды, состоящая из взаимодействующих индивидов, групп, институтов, культур и т. д.

В. Касьянов, В. Нечипуренко, О. Медведева определяют социальную среду как совокупность социальных условий жизнедеятельности человека, оказывает влияние на его сознание и поведение [4; 5]. А в Российской социологической энциклопедии указано, что это общественные, материальные и духовные условия его существования, формирования и деятельности, окружающие человека (социальный слой, группу) [7].

Поскольку согласно с идеями современных исследователей [6; 8], социальная среда является объективным условием и системообразующим элементом процесса социализации, она является объектом научных исследований в различных областях (теоретическая и практическая социология, педагогика, социальная педагогика, социальная работа, социальная психология, социальная экология, социальные права).

Итак, термин «социальная среда» будем рассматривать как совокупность важных факторов (на макро- и микроуровне), влияющих на личность в процессе ее социализации, определяя ее возможности и адаптационный потенциал. Тогда специально организованные условия профессионального роста и подготовки будущих специалистов в области социального воспитания в рамках воспитывающей среды научного студенческого общества будем считать определяющими в процессе формирования образовательного пространства их профессиональной подготовки в вузе.

Рассмотрим случаи, когда социальная среда может быть воспитывающей. Как показывают исследования В. Ромайкина, термин «воспитывающая среда» имеет более долгую историю в теории и практике воспитания, чем «воспитывающее пространство» [6]. Автор отмечает, что уже в первой трети ХХ в. в работах исследователей можно найти предпосылки трактовки среды в качестве средства управления процессом становления личности ребенка: изменения социальной среды обусловливают изменения всего педагогического процесса (С. Шацкий); среда, которая создается с целью педагогического воздействия (А. Пинкевич); определенная воспитывающая среда (А. Калашников); учитель 
как организатор и руководитель воспитывающей среды (Л. Выготский); воспитание происходит только с помощью специально созданной среды (Д. Дьюи).

Н. Щуркова определяет воспитывающую среду как «совокупность окружающих ребенка обстоятельств, социально ценностных, влияющих на его личностное развитие и способствующих его вхождению в современную культуру» [10, с. 23]. Исследовательница выделяет в воспитывающей среде такие компоненты окружения:

1) предметно-пространственное (создает психологический фон, на котором разворачиваются взаимоотношения всех, кто находится в здании школы; это окружение становится фактором воспитания личности лишь в том случае, когда оно «очеловечивается», когда по предмету видится отношение, когда за вещами угадываются интересы, когда материальные средства выступают для всех школьников как условие наилучшего состояния каждого члена коллектива, когда все активно заботятся об этом мире, творчески преобразуя его предметное пространство);

2) поведенческое (единственная карта поведения, свойственного школьникам в данной школе за счет доминирования тех или иных поведенческих форм: установленные в школе интонации в общении, мимика и жесты при разговоре, позы при диалоге, характер совместной деятельности детей и педагогов, отдельные поступки школьников, конфликты, которые имеют место, и их разрешение, а также сложные ситуации этического порядка, возникающие время от времени);

3) событийное (совокупность событий, попадающих в поле восприятия воспитанника, служащие предметом оценки, поводом к размышлениям и основанием для жизненных выводов: если ребенок видит отношения там, где на поверхности лежат случай, действия, обстоятельство, то данное событие становится фактором его личностного развития, так как событие стало для него важным, так как он сопереживал случившемуся);

4) информационное культурное окружение школьника (является воспитывающим, когда: в школе есть укомплектованная библиотека и читальный зал при ней; все дети имеют учебники; педагоги в союзе с родителями делают все возможное, чтобы привлечь детей к домашнему чтению; постепенно приучают их слушать публичные выступления, приглашая гостя в школу или проводя традиционные публичные лекции в школе, организовуют конкурсы, вводят регулярные реферативные выступления школьников и конференции для старшеклассников) [10].

Итак, педагогические действия по созданию воспитывающей среды исследовательница характеризует как использование потенциала среды (ограничение действия негативных факторов среды и усиления положительных).

Термин «воспитывающее пространство», как утверждает В. Ромайкин, появился в научной литературе в 60-70 годы XX в. и был связан с обобщением экспериментальной деятельности по созданию социально-педагогических комплексов [6]. Термин «пространство» является заимствованным в сферу социальной жизни из физики, математики и предусматривает множественность объектов, между которыми установлены отношения, определяющиеся характером этих объектов и расстоянием между ними. В философском понимании пространство характеризует форму существования бытия.

Первая попытка систематизировать различные подходы к пониманию категории воспитательного пространства была сделана Н. Селивановой, которая выделяет такие его разновидности [3]: 1) педагогически целесообразно организованная среда, окружающая отдельного ребенка или множество детей класса, школы, дома; двора, микрорайона, села, малого или большого города, области (при таком понимании структурной единицей 
воспитательного пространства становятся образовательная, культурная, медицинская или другая организация, которая принимает участие в создании этого пространства, а основным механизмом создания воспитательного пространства является взаимодействие данных коллективов, объединенных единым пониманием педагогических задач, едиными принципами и подходами к воспитанию); 2) часть среды, в которой царит определенный педагогически сформированный образ (в этом случае взаимодействие всех участников процесса создания воспитательного пространства определяется моделью образа жизни школьника; механизм создания воспитательного пространства при этом аналогичный вышеуказанному); 3) динамическая сеть взаимосвязанных педагогических событий, которая собирается усилиями субъектов различного уровня (коллективных и индивидуальных) и способна выступать интегрированным условием личностного развития человека (под коллективными субъектами понимают и школу, и театр, и лечебное учреждение, и библиотеку, и учреждение дополнительного образования, но не как учреждение, а как профессиональные сообщества, которые ставят перед собой цель - воспитание личности; индивидуальными субъектами в таком случае будут педагоги, родители, дети, студенты, врачи, юристы, любые люди, встреча с которыми может превратиться для ребенка в «событие»; в этом случае механизмом создания воспитательного пространства становится «событие» детей и взрослых, в котором, ключевым технологическим моментом является их совместная деятельность).

Таким образом, сравнение содержания понятий «воспитывающая среда» и «воспитывающее пространство» позволяет утверждать, что социальная среда приобретает характеристики среды воспитывающей в результате управление объективно существующими обстоятельствами; воспитательное пространство возникает благодаря преобразовательной деятельности его субъектов; управление социальной средой позволяет актуализировать потенциально существуюие в нем ресурсы; создание воспитательного пространства обусловливает возникновение качественно новых ресурсов, развивающихся на основе конструктивной деятельности его субъектов; воспитательное пространство существует в средовом контексте, поэтому, на наш взгляд, существование воспитательного пространства неизбежно приводит к педагогизации среды и определению характеристик среды, которая воспитывает.

Анализ и обобщение исследований по проблеме создания воспитывающей среды позволили определить такие идеи, которые нужно учитывать будущим социальным педагогам при ее проектировании для дезадаптированных детей и молодежи: выделение в культурно-воспитательном пространстве микросреды отдельных культурных центров; педагогизация окружающей среды путем социально-педагогического проектирования; поиск собственной социокультурной ниши для каждого воспитанника; учет условий среды обитания ребенка для проектирования воспитывающего пространства, необходимого для гармоничного развития воспитанника; определение различных элементов воспитывающей среды (пространственное окружение, поведенческое окружение, событийное окружение, информационное окружение); создание специальных воспитывающих ситуаций.

Вышеперечисленные идеи организации практической подготовки будущих специалистов по социальному воспитанию дезадаптированных детей и молодежи, по нашему мнению, можно осуществить за счет создания условий для проведения научных исследований, способствующих успешной профессионализации будущих социальных педагогов. В ходе написания курсовых и дипломных работ студенты имеют возможность проводить эксперимент на базах социально-педагогической практики в 
общеобразовательных учебных заведениях и специализированных интернатах, а также социальных службах, что позволяет повысить их уровень готовности к практической деятельности с дезадаптированными детьми и молодежью.

Для обеспечения создания профессионально направленного образовательного пространства подготовки будущих специалистов в области социального воспитания на кафедре социальной педагогики Харьковского национального педагогического университета имени Г. С. Сковороды созданы условия для развития их профессиональной компетентности путем организации деятельности студенческого научного общества, участие в работе которого обеспечивает: возможность обмена опытом профессиональной деятельности; раскрытие собственного личностного потенциала; накопление опыта творческой деятельности; знакомство с профессионалами социально-педагогической сферы и расширение партнерской сети нашего университета.

Учитывая организационно-педагогические условия эффективной непрерывной практической подготовки будущих социальных педагогов в высших учебных заведениях, обоснованные 3. Фалинской (организация единой непрерывной практической подготовки будущих социальных педагогов; координация практической подготовки по схеме вуз заведение социальной и социально-педагогической сферы; наличие деловых контактов организаторов практики с работниками социальной сферы; привлечение студентов к волонтерской деятельности; формирование корпуса супервизоров [9]), мы создали систему деятельности научного студенческого сообщества. Она предполагает учет всех вышеперечисленных условий через организацию таких особенностей работы студенческого научного общества: студенты-исследователи имеют возможности для приобретения профессионального практического опыта на базах практики на протяжении всего учебного года; начинающие студенты-исследователи могут взаимодействовать со старшекурсникамисупервизорами по своей проблеме, а также участвовать в профессионально ориентированных акциях и мероприятиях, которые проводят студенты-магистранты в рамках своих научных исследований.

Важной особенностью процесса подготовки студентов в рамках деятельности студенческого научного общества является обеспечение возможности профессионального восхождения для каждого студента от наблюдателя через активного деятеля к организатору и руководителю профессиональной социально-педагогической деятельностью студентов младших курсов, выполняющих научные исследования по близкой им теме.

На первом этапе деятельности в условиях студенческого научного общества будущие социальные педагоги привлекаются к посещению тематических занятий кружка, что способствует более осознанному выбору темы будущего научного исследования и формированию устойчивой мотивации к выбранному направлению профессиональной деятельности с дезадаптированными детьми и молодежью. Далее студенты вторых - третьих курсов активно участвуют в работе кружка, выступая с сообщениями на научных конференциях и семинарах как на базе университета, так и вне его, повышая уровень когнитивной подготовки к работе с дезадаптированными детьми и молодежью. Студентыстаршекурсники привлекаются к участию в мастер-классах и практических семинарах обмена опытом, а также участию во Всеукраинских и международных конференциях, что позволяет повысить эффективность их практической готовности к профессиональной деятельности.

Диагностирование уровня профессиональной подготовки будущих социальных педагогов к работе с дезадаптированными детьми и молодежью показало, что у них 
повысился уровень мотивационной готовности к организации работы с соответствующим контингентом почти вдвое. Следует отметить и то, что показатели когнитивной готовности будущих специалистов выросли на $25 \%$, показатели личностной готовности - на $27 \%$, а практической готовности - на $20 \%$. Кроме того, во время проведения заседаний научного студенческого общества нам удалось развить у будущих социальных педагогов навыки эффективного взаимодействия студентов старших и младших курсов, достичь мобилизации совместных усилий, направленных на решение определенных проблем, что также способствовало повышению уровня их личностной и практической готовности к работе с дезадаптированными детьми и молодежью.

Создание вышеуказанных условий в процессе подготовки будущих социальных педагогов к работе с дезадаптированными детьми и молодежью, по нашему мнению, способствует повышению ее эффективности посредством: 1) осуществления практической подготовки не только в вузах, а и на базах практики; 2) привлечения студентов к волонтерской деятельности с дезадаптированными детьми и молодежью, обеспечивающее повышение их мотивации к работе в этом направлении; 3) формирования корпуса супервизоров из успешных студентов-старшекурсников (победителей и призеров научных конференций и конкурсов), с помощью которого студенты смогут определить уровень собственной готовности к работе.

Перспективными направлениями исследования проблемы подготовки будущих социальных педагогов к работе с дезадаптированными детьми и молодежью являются создание модели профессионально направленного образовательного пространства и технологии проектирования соответствующей образовательной среды.

\section{Литература}

1. Большой словарь по социологии (проект) [Электронный ресурс]. - Режим доступа : www.rusword.com.ua 2. Воронин А. С. Словарь терминов по общей и социальной педагогике / А.С. Воронин. - Екатеринбург: ГОУ ВПО УГТУ - УПИ, 2006. - 135 с. 3. Воспитательное пространство как объект педагогического исследования/ под ред. Н. Л. Селивановой. - Калуга : Институт усовершенствования учителей, 2000. - 248 с. 4. Касьянов В. Социология права: словарь специальных терминов/ В. Касьянов, В. Нечипуренко [Электронный ресурс]- Режим доступа: http://nashol.com/2012061265582/sociologiya-prava-kasyanov-v-v-nechipurenko-v-n.

5. Медведева Е. С. Словарь терминов по теории социальной работы / Е. С. Медведева: [учеб. пособ.] / Е.С.Медведева; под ред. проф. Е.П. Агапова. - Ростов-на Дону : Центр универсальной полиграфии, 2009. - 324 с. 6. Ромайкин В. Ю. Соотношение понятий «воспитывающая среда» и «воспитательное пространство» / [Электронный ресурс]. - Режим доступа : http // vestnik.yspu.org/releases/pedagoka_i 7. Российская социологическая энциклопедия / под общей ред. академика РАН Г. В. Осипова / [Электронный ресурс].Режим доступа : http://www.yspu.yar.ru 8. Социология. Словарь / сост. Т. Е. Зерчанинова. Екатеринбург: УрАГС, 2006. - 64 с. 9. Фалинська 3. 3. Практична підготовка майбутніх соціальних педагогів у вищих навчальних закладах: дис. на здобуття наук. ступеня канд. пед. наук: 13.00.04 / 3. 3. Фалинська. - Л., 2006. - 284 с. 10. Щуркова Н. Е. Практикум по педагогической технологии / Е. Н. Щуркова. - Москва : Педагогическое общество России, 1998. - 234 c. 